\title{
Quantitative Analysis of Central Nervous System Tissues (CNST) in Beef By-Products in Retail Market
}

\author{
Dong Gyun Lim and Mooha Lee* \\ Department of Agricultural Biotechnology, Seoul National University, Seoul 151-921, Korea
}

\begin{abstract}
This study was carried out to investigate the applicability of the detection of central nervous system tissues (CNST) in beef by-products in retail market. Beef by-products including large intestine, brain, spinal cord, liver, lung, spleen and heart were purchased and tested for the presence of CNST using an ELISA method. The ELISA test was evaluated and showed a high correlation coefficient by a standard curve $(\mathrm{R}$ value $=0.999)$. Based on the analytical instruction, the positive indication of the CNST contamination of brain and spinal cord was detected above $0.1 \%$ but large intestine, liver, lung, spleen, and heart was negative. Result suggests that the ELISA method is applicable to a real meat system and may provide a method to ensure confidence for consumer against bovine spongiform encephalopathy (BSE).
\end{abstract}

Key words: beef by-products, central nervous system tissue, ELISA

\section{Introduction}

Consumer's concern about bovine spongiform encephalopathy (BSE), a disease believed to be transmitted by consumption of central nervous system tissue (CNST) (Hill et al., 1997). BSE is characterized by the accumulation of an abnormal isoform of the cellular prion protein in CNST (Lucker et al., 2005). Transmission of the agent from animals to human is considered to occur by consumption of contaminated meat products from BSE infected cattle. Investigations on the etiology of the disease showed that BSE agent is the cause of variant CreutzfeldtJakob disease (vCJD) in human (Almond and Pattison, 1997; Bruce et al., 1997). Such concerns have been exacerbated by confirmation that the infectious agent, a prion isolated from BSE-infected cattle, shares a number of characteristic in biological and structural features with the infectious agent of VCJD in humans (Brown et al., 2001; Bruce et al., 1997; Choi et al., 2007; Collinge et al., 1996; Scott et al., 1999). $\mathrm{PrP}^{\mathrm{SC}}$, which the meaning of abnormal prion protein, is the main and probably the only component of the infectious BSE agent (Legname et al., 2004). Shortly after the identification of BSE in cattle,

\footnotetext{
*Corresponding author: Mooha Lee, Department of Agricultural Biotechnology, Seoul National University, Seoul 151-921, Korea. Tel: 82-2-880-4820, Fax: 82-2-873-4804, E-mail: moohalee@ snu.ac.kr
}

concerns that this disease could be transmitted to humans contacting or consuming beef and beef products emerged (Brown et al., 2001).

CNST such as brain and spinal cord, which are classified as specified risk materials (SRM), are regarded to be main source of infection and carry up to $95 \%$ of the total infectivity (SSC, 1998). Oral route for infection requires a high level of infectiosity as being in CNST (Verdrager, 1996). Many countries that have confirmed the presence of BSE in their domestic cattle have taken the measure of requiring control and removal of SRM from carcasses of cattle of a defined age. European Union has banned SRM from food production (Commission Decision 2000/418/ EC, 2000). USDA-FSIS issued regulations regarding control and removal of SRM from cattle during preparation of beef products. These SRMs included the brain, spinal cord, skull, eyes, trigeminal ganglia, vertebral column (excluding the vertebrae of the tail, the transverse processes of the sacrum) and dorsal root ganglia of cattle with ages 30 months or older, as well as the tonsils and lateral ileum of all cattle (Lopes et al., 2006; WHO, 1997). Potential human exposure routes include consumption of brain ( $64 \%$ of the total on average), spinal cord (26\%), trigeminal ganglia (2.6\%), dorsal root ganglia $(3.8 \%)$ and ileum (3.3\%) (EC, 1998).

A regulation in Korea does not allow the presence of CNST in meat and meat by-products but it is not strictly prohibited at slaughterhouses due to the absence of proper 
detection method. At present, Korean is consuming both domestic and imported meats and, traditionally, a spinal cord, brain, and intestine have been consumed which may cause the risk for people if the cattle were infected of BSE. Consequently, the related authorities have to give more attention on SRM removal from beef production. Analytical test for CNST contamination on meat and its by-products is essential to ensure consumer confidence and allay consumer fears of BSE in meat products. However, there is limited report available for CNST contents in real meat by-products being distributed in retail market. In this respect, the present study was carried out to investigate the content of CNST in beef byproducts purchased from the domestic retail market in Korea using ELISA method and tested its applicability in industry.

\section{Materials and Methods}

\section{Sample collection}

Beef by-products were purchased from 5 different retail meat shops located in Seoul, Korea. By-products samples included a large intestine, brain, spinal cord, liver, lung, spleen, and heart of domestic origin and were kept on ice for transport to the laboratory and stored in a refrigerator at $4^{\circ} \mathrm{C} \pm 2$.

\section{Sample preparation for ELISA-based analysis}

Samples were prepared by immersing a Dacron ${ }^{\circledR}$ fibertipped, sterile swab (Fisher Scientific, USA) five times into the sample while rotating the swab. The swab was removed in a 2-mL test tube containing $1 \mathrm{~mL}$ of $0.5 \%$ SDS sample dilution buffer (Ridascreen, R-Biopharm, Germany). The aliquot samples were stored at $4^{\circ} \mathrm{C}$ and measured at a day after collection of samples. These procedures for the sample preparation were followed by a manufacture's instruction (Art, No. R6703, 10/5, Ridascreen ${ }^{\mathrm{TM}}$ risk material, Rbiopharm, AG, Germany).

\section{Testing protocol}

This assay was carried out as described by Hossner et al. (2006), Lim et al. (2007b), and Yesilbag and Kalkan (2005). Detection of CNST was performed on samples using a commercial ELISA-based test - the Ridascreen TM risk material 10/5 kit (R-biopharm, AG, Germany), which detects glial fibrillary acidic protein as a marker. All procedures for the assay kits were provided by the manufacturer (Art, No. R6703, 10/5, Ridascreen ${ }^{\mathrm{TM}}$ risk material, R-biopharm, AG, Germany). A $50 \mu \mathrm{L}$ aliquot of sample was transferred from each test tube to an assay well. A sufficient number of antibody-coated wells were inserted into the micro-well holder to accommodate the number of samples and all standards tested (four standards, containing $0 \%, 0.1 \%, 0.2 \%$ and $0.4 \%$ CNST composed of brain and spinal cord), were provided with the Ridascreen ${ }^{\circledR}$ assay. Enzyme conjugate $(50 \mu \mathrm{L})$ was added to each well containing four standard and samples, and the plate was incubated for $10 \mathrm{~min}$ at room temperature $\left(20-25^{\circ} \mathrm{C}\right)$. After incubation, the liquid was poured out to empty the wells, and the micro-well holder was tapped upside down thoroughly against absorbent paper, so that the liquid added earlier was completely removed from the wells. The wells were washed again with 250 $\mu \mathrm{L}$ of washing buffer and emptied as described above. A $100 \mu \mathrm{L}$ volume of substrate/chromogen mixture was added to each well and mixed thoroughly, after which time the plate was incubated for $5 \mathrm{~min}$ at room temperature in the dark. The reaction was stopped by adding $100 \mu \mathrm{L}$ of stop solution to each well. Color intensity or optical density (absorbance) was determined by photometric evaluation using a microtiter spectrophotometer (Microplate Reader 550, BioRad, USA) with a filter corresponding to $450 \mathrm{~nm}$. Results were interpreted as indicated in the Ridascreen ${ }^{\circledR}$ risk material 10/5 kit information booklet. Based on the Ridascreen ${ }^{\circledR}$ assay kit booklet, the detection limit of the kit was $0.1 \%$ for CNST contamination in meat. Values falling below detection limits were considered negative and those above it were positive (Hajmeer et al., 2006).

\section{Statistical analysis}

Standard curve and $\mathrm{R}$ value were obtained by creating a 3D Mesh Plot of SigmaPlot (Anonymous, 1999). Totally 30 samples from each beef by-products was analyzed and mean values and standard deviation was reported.

\section{Results and Discussion}

\section{Standard curve and $R$ value of a Ridascreen risk material 10/5 kit}

The performance of the Ridascreen test based on ELISA method was evaluated. Hugshon et al. (2003) reported that Ridascreen test proved consistent in its ability to detect the presence or absence of CNST. The Ridascreen test procedure was relatively easy and could be carried out within a few hours (Hajmeer et al., 2003). The analysis was a simple method and interpretation of the results was straightforward as numbers were produced at the end of 


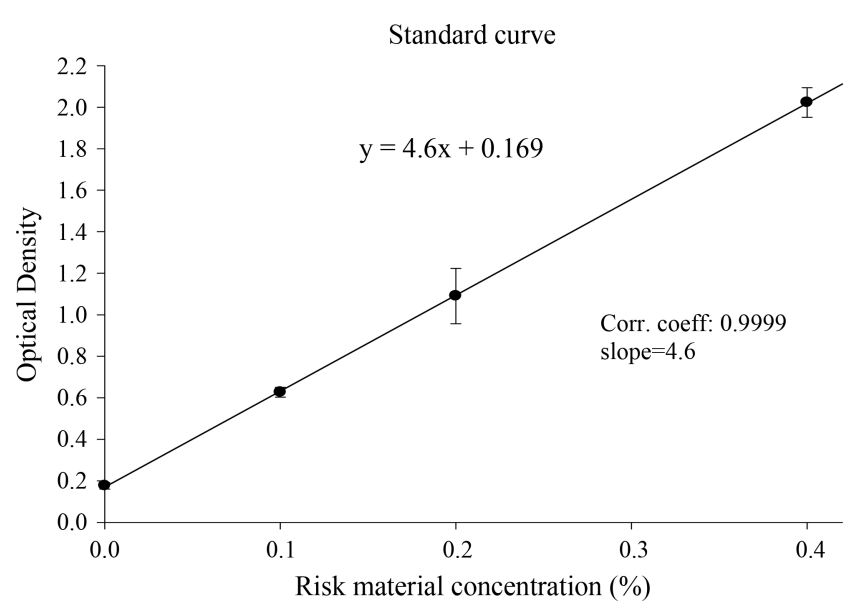

Fig. 1. Calibration curve for the standard glial fibrillary acidic protein (GFAP) ELISA detection of central nervous system tissues (CNST). Optical density was measured at $450 \mathrm{~nm}$ using a microtiter spectrophotometer.

the analysis (Hajmeer et al., 2003; Hajmeer et al., 2006). Fig. 1 shows a typical dilution curve for the GFAP (glial fibrillary acidic protein) standard used in the ELISA (Anonymous, 1999). Standards (0, 0.1, 0.2, and 0.4\% CNST composed of brain and spinal cord) provided with the Ridascreen ${ }^{\circledR}$ assay were tested. Three replications were tested for the detection of CNST. A high correlation coefficient was obtained for the standard curve $(\mathrm{R}$ value $=$ 0.999). Based on this information, the test used had a sensitivity of $0.03 \%$ for spinal cord versus $0.1 \%$ for brain (Hajmeer et al., 2003). The test was directed to GFAP, which this study showed to be more concentrated in spinal cord than in brain (Hajmeer et al., 2003). Bozzetta et al. (2006) reported that this Ridascreen ${ }^{\circledR}$ kit assay is a reliable tool for monitoring CNST contamination in meat because test performance showed high sensitivity and specificity (97.9 and 97.4\%, respectively) for a cut-off value between positive and negative at a CNST concentration of $0.049 \%$. The critical point in this procedure was the sampling method. Since the swab was recommended to get the sample of CNST contamination, the standard of the area and how to swab were very important. The procedure was, therefore, dependent on who conducted the sampling.

\section{Detection of CNST of beef by-products}

As indicated in the Ridascreen ${ }^{\circledR}$ risk material 10/5 kit information booklet, the detection limit of the kit was $0.1 \%$ for CNST contamination in meat and its by-products. Therefore, samples having on CNST (\%) equal or more than $0.1 \%$ level were accepted positive (Hajmeer et al., 2006; Lim et al., 2007a).

Table 1 presents the CNST levels on beef by-product samples purchased from the retail market. High levels of CNST were detected above $0.1 \%$ in spinal cord $(0.71 \%)$ and brain $(0.63 \%)$, while the contents in large intestine, liver, lung, spleen, and heart were less than $0.1 \%$. CNST such as brain and spinal cord which are classified as high SRM are regarded to be main source of infection and carry up to $95 \%$ of the total infectivity (SSC, 1998). Reports indicate that the GFAP is a major part of the glial filaments in astrocytes that are restricted to CNST such as brain and spinal cord (Eng and Lee, 1995), and higher levels of the GFAP are found in spinal cord (55-220 $\mu \mathrm{g} /$ $\mathrm{mg}$ ) compared with brain $(9-55 \mu \mathrm{g} / \mathrm{mg}$ ) (Schmidt et al., 1999). The standards provided by the Ridascreen ${ }^{\circledR}$ assay kit manufacturer indicated a blend of bovine brain $(600$ ng GFAP/mg) and spinal cord (2000 ng GFAP/mg). Based on this information, the test used had a sensitivity of $0.03 \%$ for spinal cord versus $0.1 \%$ for brain (Hajmeer et al., 2003). In this study, samples such as brain and spinal cord showed higher calculated levels with above $0.1 \%$ (Table 1). These quantities indicate an inadvertent addition of meat contaminants by the producer, possibly from small amounts of spinal cord. And occasional samples contained higher levels of GFAP, which are restricted to the CNST, probably due to contamination by the carcass splitting saw, incomplete removal of the spinal cord or a chance sampling of nerve (Schmidt et al., 2002). Improper handling can lead to contamination of meat with higher amounts of spinal cord, spinal ganglia, or peripheral nervous tissue (Anil et al., 1999). CNST may be disseminated on beef carcasses from slaughterhouses and it may lead contamination in edible portion of beef. Regulations require slaughterhouses to implement measures to prevent CNST (especially those considered

Table 1. Central Nervous System Tissues (CNST) levels (\%) in meat by-products purchased from Korean retail market ${ }^{1)}$

\begin{tabular}{ccccccccc}
\hline \hline & Large intestine & Brain & Spinal cord & Liver & Lung & Spleen & Heart \\
\hline Mean $^{2)}$ & 0.07 & 0.63 & 0.71 & 0.01 & 0.04 & 0.09 & 0.04 \\
Standard deviation & 0.03 & 0.02 & 0.04 & 0.01 & 0.01 & 0.01 & 0.01 \\
\hline
\end{tabular}

${ }^{1)}$ Kit detection limit was $0.1 \%$ and values falling below detection limit were considered negative and those above it were positive (Hajmeer et al., 2006).

${ }^{2)}$ Mean value of CNST (\%) in sample $(n=30)$ 
SRM) from cross-contaminating other tissue at slaughter. From this result, the positive indication of CNST contamination of by-products such as brain and spinal cord was detected above the detection limit $(0.1 \%)$. It is assumed that removal of SRM from the slaughtered animal could be the most important consumer protection factor in BSEfree country such as Korea. This data may serve beneficial information on the strategy for avoiding SRM to consumer and provides a reference for further application, thereby offering a safer animal food.

\section{Acknowledgements}

This study was supported by the Technology Development program for Agriculture and Forestry, Ministry of Agriculture and Forestry, Republic of Korea.

\section{REFERENCES}

1. Almond, J., and Pattison, J. (1997) Human BSE. Nature 389, 437-438.

2. Anonymous. (1999) SigmaPlot for Windows Version 5.00, SPSS INC., U.S.A.

3. Anil, M. H., Love, S., Williams, S., Shand, A., Mckinstry, J. L., Helps, C. R., Waterman-Pearson, A., Seghatchian, J., and Harbour, D. A. (1999) Potential contamination of beef carcasses with brain tissue at slaughter. Vet. Rec. 145, 460-462.

4. Bozzetta, E., Nappi, R., Ru, G., Negro, M., Maurella, C., and Caramelli, M. (2006) Evaluation of an enzyme immunoassay for the detection of central nervous system tissue contamination at the slaughterhouse. J. Food Prot. 69, 2289-2292.

5. Brown, P., Will, R. G., Bradely, R., Asher, D. M., and Detwiler, L. (2001) BSE and variant Creutzfeldt Jakob disease. $B r$. Med. J. 322,841-844.

6. Bruce, M. E., Will, R. G., Ironside, J. W., Mcconnell, I., Drummond, D., Suttie, A., Mccardie, L., Chree, A., Hope, J., Birkett, C., Cousens, S. F. H., and Bostock. C. J. (1997) Transmissions to mice indicate that 'new variant' CJD is caused by the BSE agent. Nature 389, 498-501.

7. Choi, S. H., Chae, S. H., Choi, H. H., Kim, J. S., Kang, B. R., Yeo, J. S., Choi, I., Lee, Y. S., Choi, Y. H., and Park, H. S. (2007) Genomic sequence variability of the prion gene (PRNP) in Korean cattle. Asian-Aust. J. Anim. Sci. 20, 653-660.

8. Collinge, J., Sidle, K. C. L., Meads, J., Ironside, J., and Hill, A. F. (1996) Molecular analysis of prion strain variation and the aetiology of 'new variant' CJD. Nature 383, 685-690.

9. Commission Decision 2000/418/EC.(2000) Regulating the use of material presenting risk as regards transmissible sponge form encephalopathies and amending Decision 94/747/EC. Official J. 158/76.

10. Eng, L. F., and Lee, Y. L. (1995) Intermediate filaments in astrocytes. In X. Ketternmann, \& X. Ransom, Neuroglia. New York, Oxford University Press.
11. EC (European Community) (1998) Relative infectivity of specified risk materials, report of the spongiform encephalopathy assessment committee, Feb, Brussels.

12. Hajmeer, M. N., Cliver, O., and Provost, R. (2003) Spinal cord tissue detection in comminuted beef: comparison of two immunological methods. Meat Sci. 65,757-763.

13. Hajmeer, M. N., Cliver, O., and Marsden, J. L. (2006) Central nervous system tissue detection in meat from advanced meat recovery systems. Meat Sci. 72, 656-659.

14. Hill, A. F., Desbruslais, M., Joiner, S., Sidle, K. C., Gowland, I., Collinge, J., Doey, L. J., and Lantos, P. (1997) The same prion strain causes vCJD and BSE. Nature 389, 448-450.

15. Hossner, K. L., Yemm, R. S., Sonnenshein, S. E., Mason, G. L., Cummi, B.A., Reddy, M. C. S., Sofos, J. N., Scanga, J. A., Tatum, J. D., Smith, G. C., and Belk, K. E. (2006) Comparison of immunochemical and immunohistochemical method for the detection of central nervous system tissue in meat products. J. Food Prot. 69, 644-650.

16. Hughson, E., Reece, P., Dennis, M, J., and Oehlischlager, S. (2003) Comparative evaluation of the performance of two commercial kits for the detection of CNS tissue in meat. Food Additive Contam. 20, 1034-1043.

17. Legname, G., Baskakov, I. V., Cohen, F. E., DeArmond, S. J., and Prusiner, S. B. (2004) Synthetic mammalian prions. Science 305, 673-676.

18. Lim, D. G., Erwanto, Y., and Lee, M. (2007a) Comparison of stunning methods in the dissemination of central nervous system tissue on the beef carcass surface. Meat Sci. 75, 622627.

19. Lim, D. G., Kim, D. H., and Lee, M. (2007b) Effect of Spinal Cord Removal before or after Splitting and Washing on CNST Decontamination of Beef Carcasses. Asian-Aust. J. Anim. Sci. 20, 1770-1776.

20. Lopes, M., Stopforth, J. D., Sucre, K., Miksch, R. R., Giddens, E., Reddy, M. C. S., Yemm, R. S., and Samadpour, M. (2006) Alternative cutting methods to minimize transfer of nervous system tissue during steak preparation form bonein short loins. J. Food Prot. 69, 1388-1392.

21. Lucker, E., Biedermann, W., Lachhab, S. and Heuss, E. (2005) Transmissible spongiform encephalopathy: Assessment of exposure risk in the histological working environment using GC-MS detection of fatty acids as marker for central nervous tissue. Int. J. Hyg. Environ. Health 208, 391-399.

22. Scott, M. R., Will, R., Ironside, J., Nguyen, H. O. B., Tremblay, P., DeArmond, S. J., and Prusiner, S. B. (1999) Compelling transgenic evidence for transmission of bovine spongiform encephalopathy prions to humans. Proc. National academy Sci. USA, 96, 15137-15142.

23. Schmidt, G. R., Hossner, K. L., and Gould, D. H. (1999) Potential for disruption of central nervous system tissue in beef cattle by different types of captive bolt stunners. J. Food Prot. 62, 390-393.

24. Schmidt, G. R., Yemm, R. S., Hossner, K. L., Childs, K. D., O'callaghan, J. P., and Hossner, K. L. (2002) Verification of different glial fibrillary acidic protein analyses as accurate detectors of central nervous system tissue in advanced meat 
recovery products. Meat Sci. 62, 79-84.

25. SSC (The Scientific Steering Committee) (1998) Opinion on the human exposure risk (HER) via food with respect to BSE. Available: http://europa.eu.int/comm/dg24/health/sc/ssc/ out67-en.html.

26. Verdrager, J. (1996) Creutzfeldt Jakob disease. Lancet 347, 1704.

27. Yesilbag, K. and Kalkan, A. (2005) Detection of central ner- vous system tissues as BSE specified risk material in meat products in Turkey. Food Cont. 16, 11-13.

28. WHO (World Health Organization) (1997) Report of a WHO consultation on medicinal and other products in relation to human and animal transmissible spongiform encephalopathies, WHO /EMC/DIS/97.3, Geneva, WHO.

$\overline{\text { (Received 2012.1.3/Revised 2012.2.24/Accepted 2012.3.12) }}$ 